UDC 621.316 .93

DOI: 10.15587/2706-5448.2021.225492

Article type «Reports on Research Projects»

\section{Yevgeniy Trotsenko, Volodymyr Brzhezitsky, Olexandr Protsenko, Yaroslav Haran}

\title{
SIMULATION OF IMPULSE CURRENT GENERATOR FOR TESTING SURGE ARRESTERS USING FREQUENCY- DEPENDENT MODELS
}

The object of research is the equivalent circuit of an impulse current generator designed for testing surge arresters. Calculation of the impulse current generator parameters when discharging a capacitor bank to a complex nonlinear load is a difficult task for an analytical solution. Until now, the application of surge arrester frequencydependent models was limited to the problems of overvoltage computation. Surge arrester frequency-dependent models can predict the residual voltage with high accuracy. This is the reason to consider that surge arrester frequency-dependent models can be used for calculating the main parameters of impulse current generators designed for physical testing of surge arresters.

The task of determining the equivalent circuit parameters required for getting a discharge current of a given waveform and amplitude in an impulse current generator scheme with a nonlinear load was solved using circuit simulation.

This article presents the results of studying the processes in impulse current generator equivalent circuit. In the circuit a dynamic model of a surge arrester is used as the load model. For this, an equivalent circuit for the discharge path of the impulse current generator was drawn up. The parameters of the circuit elements (including the required number of capacitors and their charging voltage) are determined, which are necessary for getting a discharge current of a given standardized waveform and amplitude. The parameters of the discharge path are determined for surge arresters of three different voltage classes. It was found that the relative error when determining the residual voltage between the terminals of the surge arrester model does not exceed $3 \%$.

The work contributes to the further development of circuit simulation of surge arresters and the expansion of the scope of surge arrester dynamic models. As a result of the research performed, the possibility of using surge arrester frequency-dependent models for determining the discharge current waveform in impulse current generators is shown. The research performed is relevant due to the fact that surge arresters have become a main tool for protecting the insulation of electrical network equipment against external and internal overvoltages.

Keywords: impulse current generator, surge arrester, high-voltage capacitor bank.

\section{Introduction}

Surge arresters are designed to protect the insulation of electrical equipment against switching and lightning overvoltages. Due to their ability to limit any kind of overvoltage, these surge protective devices have become an essential attribute in electrical installations of all voltage classes. Each surge arrester has a number of important characteristics that should be taken into account when choosing it. One of the main characteristics of a surge arrester is the residual voltage, that is, the voltage that appears between its terminals during the passage of a discharge current through it. It is the peak value of the residual voltage during the passage of switching current impulse and lightning current impulse that mainly characterizes the protective properties of the surge arrester. The surge arrester manufacturers indicate these values in kilovolts in their product brochures. The end consumer of surge arresters can check these figures only with the help of such a high-voltage impulse installation as an impulse current generator. In addition to tests for determining the residual voltage, impulse current generators are being developed for testing with a long duration current impulses [1]. One of the major components of an impulse current generator is a high-voltage capacitor bank. To obtain the required impulse current waveform, the capacitor bank is first charged and then discharged to the test object using switching devices. If the parameters of the test object are linear, then ready-made relations [2], which have been used for several decades, can be used to calculate the impulse current generator parameters. However, in this case, the test object is a surge arrester, which varistors have a highly non-linear current-voltage characteristic. Calculation of the impulse current generator parameters when discharging a capacitor bank to a nonlinear load is a new task of particular complexity. In addition to the above, it should be noted that the surge arrester is characterized not just by a nonlinear, but by a dynamic nonlinear current-voltage 
characteristic. This means that its current-voltage characteristic is different for fast-front and slow-front overvoltages. Therefore, for example, for switching and lightning current impulses of the same amplitude, different voltage drops will appear between the terminals of the surge arrester. This property is fairly well reproduced by the frequencydependent equivalent circuits of the metal oxide surge arrester [3-5]. Dynamic models of surge arresters have been repeatedly studied in various publications [6-8], where their high accuracy was confirmed. This is the reason to believe that the dynamic models of surge arresters can be used to compute the main parameters of an impulse current generator designed for full-scale testing of surge arresters.

Therefore, it is urgent to develop effective approaches to calculating the parameters of high-voltage impulse installations, taking into account new achievements in the field of circuit simulation.

Thus, the object of research is the equivalent circuit of an impulse current generator designed for testing surge arresters.

In its turn, the aim of the article is to determine the electrical parameters of the impulse current generator circuit required to obtain a test current impulse of a given amplitude and waveform in a discharge path with a surge arrester.

\section{Methods of research}

Surge arrester is a protective device and under operating conditions currents directly related to the impact of lightning will pass through it. For this reason, surge arresters must be tested with impulse currents having waveform similar to lightning currents. Besides the amplitude, the waveform of the current impulse is determined by two more parameters that characterize the change in current over time. These are the front time $T_{1}$ and the time to half the peak $T_{2}$. The first of these parameters conventionally characterizes the current rise time to the maximum, and the second, respectively, the time until the current is halved compared with maximum. Accordingly, the impulse waveform is written as a $T_{1} / T_{2}$ ratio. For testing surge arresters with a lightning current impulse, the impulse current waveform of $8 / 20 \mu$ s is adopted. Therefore, an impulse current generator must reproduce such a current in high-voltage laboratory.

As noted above, the major components of an impulse current generator are high-voltage capacitors. In this work, IC-50-3 capacitors were chosen as an element base. These capacitors have the following characteristics: rated voltage is $50 \mathrm{kV}$; nominal capacity is $3 \mu \mathrm{F}$; internal inductance of the capacitor is $40 \mathrm{nH}$. Models of three typical surge arresters designed for use in networks with a voltage class of $6 \mathrm{kV}, 10 \mathrm{kV}$ and $35 \mathrm{kV}$, respectively, were selected as test objects. The aim of this article is not to study the properties of surge arresters from any particular manufacturer. The selected devices have typical characteristics for their voltage classes. Moreover, most of the surge arresters from different manufacturers have, albeit different, but in general, similar protective characteristics. For these reasons, in order to avoid possible misunderstandings, the authors do not indicate the country and manufacturer of the surge arresters. The main research scheme is shown in Fig. 1.

In Fig. 1: $R_{1}, R_{2}, L_{1}, L_{2}$ and $C_{1}$ are linear elements of surge arrester model, in turn, $G_{1}$ and $G_{2}$ are nonlinear elements of the surge arrester model. The calculation of the numerical values of the parameters of the surge arrester model should be carried out in accordance with the procedure given in [3]. Simulation of the electrical circuit in Fig. 1 was performed using the Micro-Cap 12 circuit simulation program [9]. Modeling of nonlinear elements $G_{1}$ and $G_{2}$ of the surge arrester model in Fig. 1 was performed using a voltage-controlled current source (NTIofV) model in accordance with the approach proposed in [10]. The rest of the elements in Fig. 1 refer to the equivalent circuit of the impulse current generator: $C_{2}$ is storage capacitor charged to a certain voltage; $R_{3}$ is resistor; $L_{3}$ is the inductance that is the sum of the parasitic inductances of the capacitor bank, the parasitic inductances of the connecting wires, the parasitic inductance of the resistor, etc. Switch $S W_{1}$ is a model of a controlled switch, with the help of which the charged capacitor $C_{2}$ is discharged to $L_{3}, R_{3}$ and the elements of the surge arrester model $\left(R_{1}, R_{2}, L_{1}, L_{2}, C_{1}, G_{1}\right.$ and $\left.G_{2}\right)$.

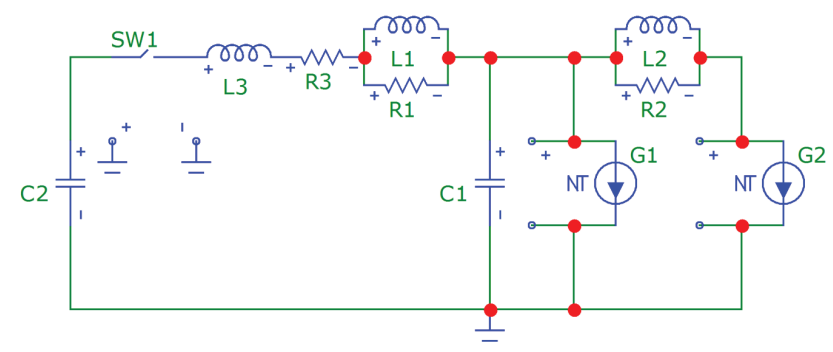

Fig. 1. Impulse current generator circuit with a surge arrester as a test object

This scheme can be used for step-by-step calculation of the impulse current generator parameters. Using the circuit, one can check the influence of the permissible inductance and active resistance of the discharge path on the waveform and amplitude of the discharge current. Also, using the circuit, one can check the influence of the selected number of capacitors and the value of their charging voltage on the waveform and amplitude of the discharge current passing through a surge arrester (of a certain voltage class). The main goal of circuit simulation is to determine the circuit element parameters necessary to obtain a discharge current with $10 \mathrm{kA}$ amplitude and $8 / 20 \mu$ s waveform passing through a surge arrester. The reference point for determining the nonlinear element values of the model (Fig. 1) is the surge arrester residual voltage precisely at $8 / 20 \mu$ s waveform and $10 \mathrm{kA}$ amplitude [10]. The simulation results obtained using the impulse current generator equivalent circuit are given in the next section of the paper.

\section{Research results and discussion}

As a result of simulation, the following was established. Hereinafter, the final data from the entire data set obtained as a result of multivariate analysis (Stepping) are presented.

In order to obtain the required discharge current waveform in a circuit with a $35 \mathrm{kV}$ network surge arrester, 12 IC-50-3 capacitors are required, connected in series-parallel in accordance with Fig. 2. The circuit parameters (Fig. 1) can be as follows: capacitor bank capacitance $C_{2}=4 \mu \mathrm{F}$, discharge path inductance $L_{3}=8 \mu \mathrm{H}$, discharge path active resistance $R_{3}=0.33 \Omega$. To obtain a discharge current with $10 \mathrm{kA}$ amplitude and $8 / 20 \mu$ s waveform, the capacitor bank must be charged to $144.2 \mathrm{kV}$ voltage. 


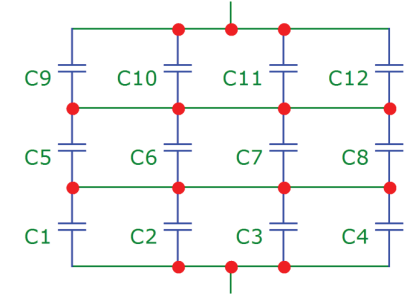

Fig. 2. Connection diagram of IC-50-3 capacitors into a capacitor bank for testing surge arresters

The waveform of the discharge current, the voltage drop between the surge arrester terminals and the absorbed energy are shown in Fig. 3. Hereinafter, the screen capture (screenshot) of the Micro-Cap 12 circuit simulation program [9] is presented.

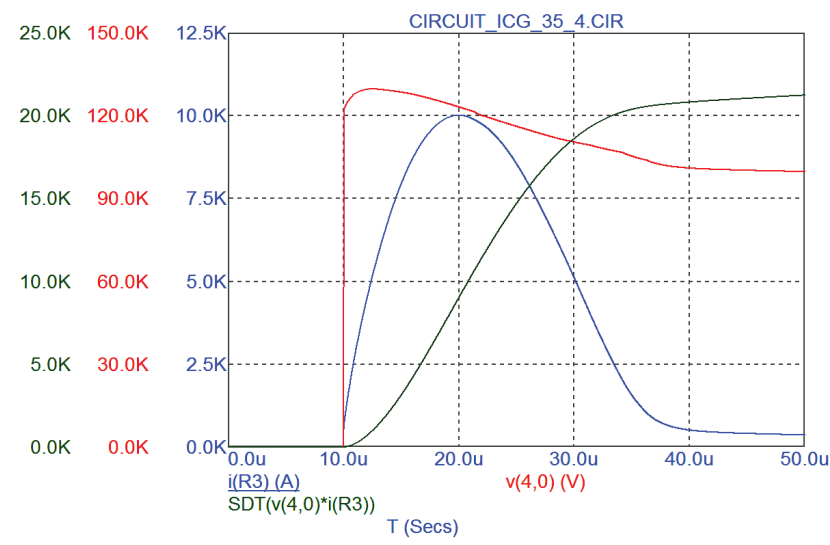

Fig. 3. Evaluation of discharge current, residual voltage and absorbed energy when testing a $35 \mathrm{kV}$ network surge arrester

For the surge arrester selected, the technical passport value of the residual voltage is $126.0 \mathrm{kV}$ at a discharge current with $10 \mathrm{kA}$ amplitude and $8 / 20 \mu$ s waveform. The value obtained in the simulation is $129.66 \mathrm{kV}$. The relative error was calculated using the formula (1) and amounted to $+2.91 \%$.

$$
\xi=\frac{V_{r}^{\prime}-V_{r}}{V_{r}} \cdot 100, \%
$$

where $V_{r}^{\prime}$ is the peak value of the residual voltage $(\mathrm{kV})$ appearing between the surge arrester terminals resulting from the simulation; $V_{r}$ is technical passport peak value of the residual voltage $(\mathrm{kV})$ for the selected surge arrester.

The energy absorbed by the surge arrester is $21.24 \mathrm{~kJ}$. Hereinafter, the energy value was determined using the built-in «SDT» function of the Micro-Cap 12 circuit simulation program [9]. This built-in function corresponds to the analytical function for energy computation:

$$
W(t)=\int_{t_{0}}^{t} u(t) i(t) \mathrm{d} t,
$$

where $W(t)$ is energy $(\mathrm{J})$ absorbed by the surge arrester as a function of time; $u(t)$ is residual voltage $(\mathrm{V})$ appeared between the surge arrester terminals as a function of time; $i(t)$ is discharge current (A) passing through the surge arrester; $t_{0}$ is moment of time when a voltage drop appears between the surge arrester terminals, $\mathrm{s}$ t $t$ is current moment of time, s.
Using the procedure given in [3], the parameters of the surge arrester model shown in Fig. 1 were determined. For a $35 \mathrm{kV}$ network surge arrester model the following values were obtained: $L_{1}=0.121 \mu \mathrm{H}, R_{1}=60.5 \Omega, L_{2}=9.075 \mu \mathrm{H}$, $R_{2}=39.325 \Omega, C_{1}=165.289 \mathrm{pF}$.

In order to physically implement the circuit in Fig. 2, high-voltage capacitors must be mounted on insulators to provide the required insulation from the ground. For example, the tanks of capacitors $C_{5}-C_{8}$ should be insulated from the grount by $50 \mathrm{kV}$, while tanks of capacitors $C_{9}-C_{12}$ should be insulated from the ground by $100 \mathrm{kV}$. For this purpose, it is proposed to use the elements of the impulse voltage generator installed in the high-voltage laboratory of the Department of Theoretical Electrical Engineering of the National Technical University of Ukraine «Igor Sikorsky Kyiv Polytechnic Institute» (Fig. 4). The balancing resistors of the capacitor bank are not shown in Fig. 4.

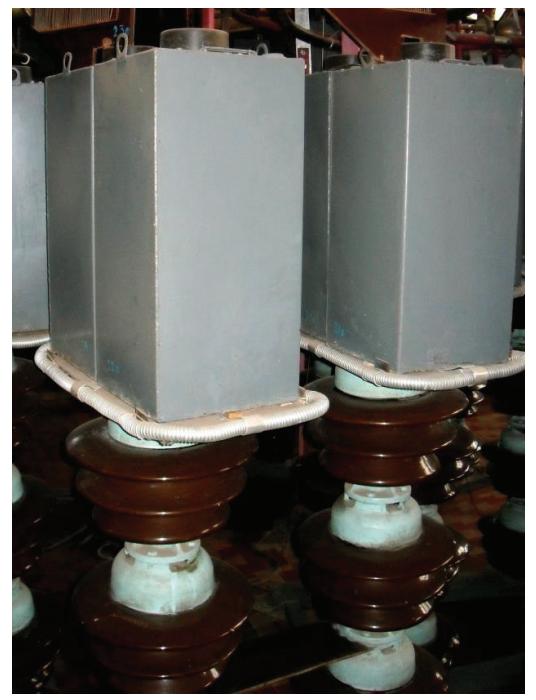

Fig. 4. Installation of IC-50-3 capacitors on support insulators to provide the necessary insulation from the ground in the impulse voltage generator

For testing $10 \mathrm{kV}$ and $6 \mathrm{kV}$ network surge arresters, it is proposed to use the same capacitor bank, adjusting only the charging voltage of the capacitors and the inductance. This inductance is realized in the form of an additional coil, which inductance is also counted in $L_{3}$ in Fig. 1.

In order to obtain the required discharge current waveform in a circuit with a $10 \mathrm{kV}$ network surge arrester, the circuit parameters can be as follows: capacitor bank capacitance $C_{2}=4 \mu \mathrm{F}$, discharge path inductance $L_{3}=13 \mu \mathrm{H}$, discharge path active resistance $R_{3}=0.33 \Omega$. To obtain a discharge current with $10 \mathrm{kA}$ amplitude and $8 / 20 \mu$ s waveform, the capacitor bank must be charged to $59.8 \mathrm{kV}$ voltage. The waveform of the discharge current, the voltage drop between the surge arrester terminals and the absorbed energy are shown in Fig. 5.

For the surge arrester selected, the technical passport value of the residual voltage is $39.6 \mathrm{kV}$ at a discharge current with $10 \mathrm{kA}$ amplitude and $8 / 20 \mu \mathrm{s}$ waveform. The value obtained in the simulation is $39.39 \mathrm{kV}$. According to (1) the relative error is $-0.53 \%$. The energy absorbed by the surge arrester is $5.9 \mathrm{~kJ}$. The parameters of surge arrester model in Fig. 1: $L_{1}=0.025 \mu \mathrm{H}, R_{1}=12.5 \Omega$, $L_{2}=1.875 \mu \mathrm{H}, R_{2}=8.125 \Omega, C_{1}=800.0 \mathrm{pF}$. 


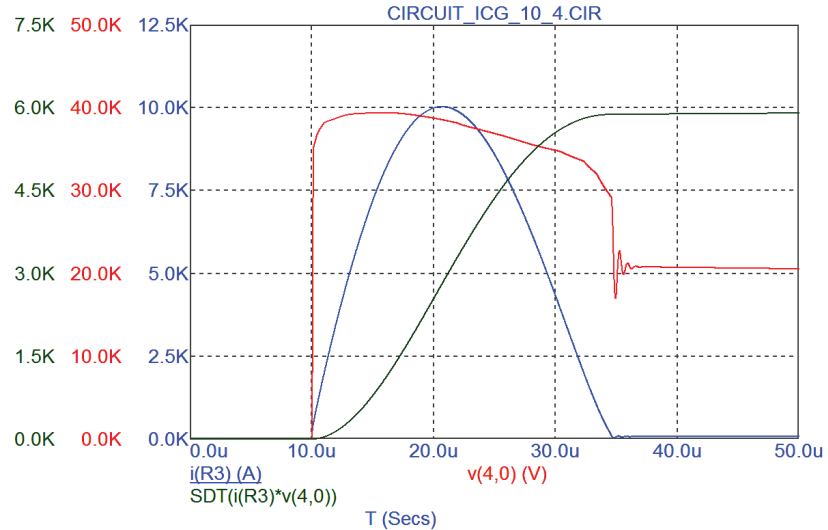

Fig. 5. Evaluation of discharge current, residual voltage and absorbed energy when testing a $10 \mathrm{kV}$ network surge arrester

In order to obtain the required discharge current waveform in a circuit with a $6 \mathrm{kV}$ network surge arrester, the circuit parameters can be the same as in the previous case: capacitor bank capacitance $C_{2}=4 \mu \mathrm{F}$, discharge path inductance $L_{3}=13 \mu \mathrm{H}$, discharge path active resistance $R_{3}=0.33 \Omega$. To obtain a discharge current with $10 \mathrm{kA}$ amplitude and $8 / 20 \mu$ s waveform, the capacitor bank must be charged to $43.1 \mathrm{kV}$ voltage. The waveform of the discharge current, the voltage drop between the surge arrester terminals and the absorbed energy are shown in Fig. 6.

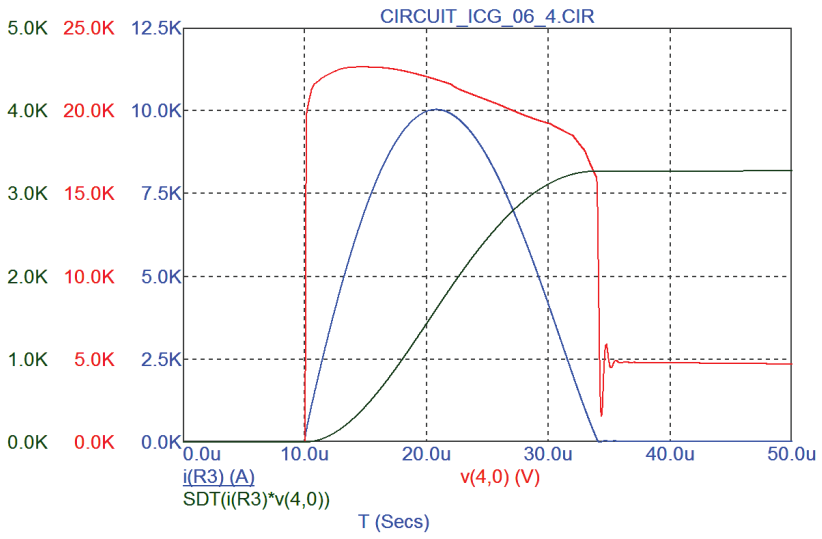

Fig. 6. Evaluation of discharge current, residual voltage and absorbed energy when testing a $6 \mathrm{kV}$ network surge arrester

For the surge arrester selected, the technical passport value of the residual voltage is $22.4 \mathrm{kV}$ at a discharge current with $10 \mathrm{kA}$ amplitude and $8 / 20 \mu$ s waveform. The value obtained in the simulation is $22.63 \mathrm{kV}$. According to (1) the relative error is $+1.03 \%$. The energy absorbed by the surge arrester is $3.27 \mathrm{~kJ}$. The parameters of surge arrester model in Fig. 1: $L_{1}=0.019 \mu \mathrm{H}, R_{1}=9.5 \Omega$, $L_{2}=1.425 \mu \mathrm{H}, R_{2}=6.175 \Omega, C_{1}=1053.0 \mathrm{pF}$.

As one can see, for testing surge arresters of various voltage classes either $6 \mathrm{kV}$ or $10 \mathrm{kV}$, it is possible to use the same impulse current generator with a slight variation of its parameters.

The development and expansion of the application field of surge arrester dynamic models is promising due to the fact that this category of protective devices has become practically mandatory for protecting the insulation of electrical network equipment from various overvoltages. Therefore, experimental and theoretical studies aimed at reducing the time spent on calculating the parameters of impulse installations for testing surge arresters are important. According to [2], the integral-differential equation of the discharge current for the impulse current generator equivalent circuit has the form:

$$
L \frac{d i}{d t}+R i+\frac{1}{C} \int i \mathrm{~d} t=U_{0},
$$

where $L$ is discharge path inductance; $R$ is discharge path active resistance; $C$ is capacitor bank capacitance; $U_{0}$ is voltage the capacitor bank is charged to.

Assuming the resistance $R$ is nonlinear, replacing $u_{R}=R i$, then dividing equation (3) on the left and right side by $L$, one get:

$$
\frac{d i}{d t}+\frac{u_{R}}{L}+\frac{1}{L C} \int i \mathrm{~d} t=\frac{U_{0}}{L}
$$

Differentiating equation (4) on the left and right side, one obtains the differential equation of the discharge in the impulse current generator with a nonlinear load:

$$
\frac{\mathrm{d}^{2} i}{\mathrm{~d} t^{2}}+\frac{1}{L} \frac{\mathrm{d} u_{R}}{\mathrm{~d} t}+\frac{1}{L C} i=0 .
$$

There is no general analytical solution to this equation. In addition, equation (5) is only valid if the surge arrester is modeled as a single nonlinear resistor. However, this is an oversimplification, which was the reason for the development of complex models of surge arresters with a dynamic current-voltage characteristic [3-5]. Therefore, the approach used in this paper is an alternative method for determining the discharge current waveform and the residual voltage waveform for a surge arrester in the discharge path of an impulse current generator. The proposed approach eliminates the need to solve the differential equation (5) and reduces the problem of determining the parameters of the impulse current generator scheme to circuit simulation. The paper presents a fragment of one of the stages of a multi-stage computation of this type of highvoltage impulse installations. Parameters $R_{3}$ and $L_{3}$ (Fig. 1) represent the total values of the corresponding parameters of the load and elements of the discharge path of the impulse current generator (buses, spark gaps, shunt, contactors, additional coil, etc.). Refinement of the active resistance $R_{3}$ and inductance $L_{3}$ is performed at the next stage and is the subject of another scientific research.

\section{Conclusions}

In this article, it is shown for the first time that dynamic models of surge arresters can be directly used to determine the main parameters of an impulse current generator designed for full-scale testing of surge arresters. It is also shown that with a help of circuit simulation, it is possible to select the parameters of the circuit elements necessary to obtain a discharge current with a given amplitude and waveform, which must pass through the surge arrester according to the test conditions. This approach has shown its effectiveness for models of various surge arresters designed for use in networks with different voltage classes. The paper presents the graphs of the discharge current, the residual voltage appearing 
between the surge arrester terminals and the absorbed energy obtained as a result of simulation. The presented approach greatly simplifies the procedure for determining the circuit parameters of impulse current generators designed for testing surge arresters.

\section{References}

1. Prasertsang, C., Triuattanapiruk, N. Yutthagowith, P. (2013). A long duration impulse current generator for testing surge arresters in distribution systems. 2013 10th International Conference on Electrical Engineering/Electronics, Computer, Telecommunications and Information Technology. Krabi, 1-4. doi: http://doi.org/10.1109/ecticon.2013.6559579

2. Beyer, M., Boeck, W., Möller, K., Zaengl, W. (1986). Hochspannungstechnik: theoretische und praktische grundlagen für die anwendug. Berlin: Springer-Verlag, 362. doi: http://doi.org/ 10.1007/978-3-642-61633-4

3. Modeling of metal oxide surge arresters. (1992). IEEE Transactions on Power Delivery, 7 (1), 302-309. doi: http://doi.org/ 10.1109/61.108922

4. Pinceti, P., Giannettoni, M. (1999). A simplified model for zinc oxide surge arresters. IEEE Transactions on Power Delivery. 14 (2), 393-398. doi: http://doi.org/10.1109/61.754079

5. Magro, M. C., Giannettoni, M., Pinceti, P. (2004). Validation of $\mathrm{ZnO}$ Surge Arresters Model for Overvoltage Studies. IEEE Transactions on Power Delivery, 19 (4), 1692-1695. doi: http:// doi.org/10.1109/tpwrd.2004.832354

6. Meister, A., Shayani, R., De Oliveira, M. (2012). Comparison of metal oxide surge arrester models in overvoltage studies. International Journal of Engineering, Science and Technology, 3 (11), 35-45. doi: http://doi.org/10.4314/ijest.v3i11.4s

7. Vita, V., Mitropoulou, A. D., Ekonomou, L., Panetsos, S., Stathopulos, I. A. (2010). Comparison of metal-oxide surge arresters circuit models and implementation on high-voltage transmission lines of the Hellenic network. IET Generation,
Transmission E Distribution, 4 (7), 846-853. doi: http://doi.org/ 10.1049/iet-gtd.2009.0424

8. Peppas, G. D., Naxakis, I. A., Vitsas, C. T., Pyrgioti, E. C. (2012). Surge arresters models for fast transients. 2012 International Conference on Lightning Protection (ICLP). doi: http:// doi.org/10.1109/iclp.2012.6344285

9. Micro-Cap 12. Electronic Circuit Analysis Program. Reference Manual (2018). Sunnyvale: Spectrum Software, 1098. Available at: http://www.spectrum-soft.com/download/rm12.pdf

10. Trotsenko, Y., Brzhezitsky, V., Masluchenko, I. (2017). Study of surge arrester model under influence of various current pulses. Technology Audit and Production Reserves, 1 (1 (33)), 44-48. doi: http://doi.org/10.15587/2312-8372.2017.92244

Yevgeniy Trotsenko, PhD, Associate Professor, Department of Theoretical Electrical Engineering, National Technical University of Ukraine «Igor Sikorsky Kyiv Polytechnic Institute», Kyiv, Ukraine, ORCID: http:// orcid.org/0000-0001-9379-0061, e-mail: y.trotsenko@kpi.ua

Volodymyr Brzhezitsky, Doctor of Technical Sciences, Professor, Department of Theoretical Electrical Engineering, National Technical University of Ukraine «Igor Sikorsky Kyiv Polytechnic Institute», Kyiv, Ukraine, ORCID: http://orcid.org/0000-0002-9768-7544, e-mail:v.brzhezitsky@kpi.ua

Olexandr Protsenko, PhD, Associate Professor, Department of Theoretical Electrical Engineering, National Technical University of Ukraine «Igor Sikorsky Kyiv Polytechnic Institute», Kyiv, Ukraine, ORCID: http:// orcid.org/0000-0002-7719-3336, e-mail: apro54@ukr.net

Yaroslav Haran, PhD, Assistant, Department of Theoretical Electrical Engineering, National Technical University of Ukraine «Igor Sikorsky Kyiv Polytechnic Institute», Kyiv, Ukraine, ORCID: http:// orcid.org/0000-0003-3242-9218, e-mail: y.garan@kpi.ua 